\title{
The Ethical and Social Decision to Use Information Technology: Case of Tablet Technology by University Students in the State of Kuwait
}

\author{
Hasan A Abbas \\ Dept. of Quantitative Methods and Information Systems, College of Business Administration, \\ Kuwait University, Kuwait
}

\begin{abstract}
The innovation of technologies is flourishing on weekly basis. Since the introduction of iPad by Apple into the technology market, the face of computing is consecutively changing in a manner of light. This paper is an exploratory study that presents the adoption and usages of such technology in an Arabian country. More precisely, our goal in this project is to study the most frequent types of uses among college level students in the State of Kuwait.
\end{abstract}

Keywords: Tablet technology, iPad, exploratory study, factor analysis.

\section{Introduction}

State of Kuwait is considered one of the open societies in the Gulf region and even among the middle eastern countries. Kuwait is characterized to be open society, democratic, freedom of speech and opinion, and economically strong and solid. For those and many different reasons, the information technology adoption and increase is distinctive, compared to other Gulf countries such as Saudi Arabia (highly conservative), United Arab Emirates (no democracy,) and Iran (poor economy).

After being the first to use and adopt the Internet (years ago) in the Arabian region, Kuwait is trying to be the leader and first to adopt and distribute the new technology among its people, precisely among high school and college level students. The Ministry of Education announced three years ago its strategy that was called the "Electronic School Briefcase". Since that time, the Ministry of Education changed its plan many times. At the beginning, the plan was to distribute CD's over high school senior level students. The plan then changed into a flash memory, which is a plan that was finally executed and been adopted six months ago under the Minister of Education Mr. Ahmad Al-Mulaifi.

Because of the political concern in the State of Kuwait regarding the importance of adopting the new technology in the education system in the small State, our research focus on the types of uses of iPad among college students. In the following sections we will cover different aspects of the project. Section 2 discusses briefly the political base and debate in the State regarding the adoption of information technologies in the public school. Section 3 presents the tablet technology uses and our research problem. Section 4 presents the literature review. Section 5 discusses the statistical analysis of the data. Finally, section 6 is the conclusion and the future studies.

Copyright (C) 2012 Hasan A Abbas. This is an open access article distributed under the Creative Commons Attribution License unported 3.0, which permits unrestricted use, distribution, and reproduction in any medium, provided that original work is properly cited. Contact author: Hasan A Abbas E-mail: hasan@mis.cba.edu.kw 


\section{Political Argument}

Although there were different arguments and debates among scholars, politicians, and decision makers in the Ministry of Education regarding what is the best option for the public school students, the more advanced technologies such as laptops and iPads never were been outside these discussion.

Lately Kuwait University followed the same path towards modernizing its way of teaching and its academic output. In order to satisfy its goals and to reach its objectives, the administration at Kuwait University (also the Ministry of Education lately) aims to increase the students academic performance by implementing various pedagogical projects. According to this mission, Kuwait University modernized its facilities since 7 years ago. The new building are all equipped with many computer labs, Internet connections, wireless connections (wifis), presentation projectors, latest softwares, and so forth. In the same path, there is still a discussions is going forward between administrative figures regarding equipping students with either laptops or iPads. The administration's claim is that such technologies is a minimum requirement according to today's standard of life. Today such gadgets is considered a basic academic tool where students need to perform and accomplish minimum academic requirement.

Currently Kuwait University supports all its staff members with desktops and laptops. Moreover, all its buildings and offices are equipped with latest technologies such as computer labs, Internet connections, elibrary, wifi's, smart boards, electronic registration systems, electronic educational softwares (e.g. Blackboard system), projectors, etc. In the path of enhancing its academic standards, the administration lately kept discussing to support each college student with his/her own laptop. Since then, the politician and the media kept discussing the matter whether such decision is worthwhile, costly, wise, feasible, etc.
In addition, some parties in the administration argued whether is it still valid to support students with laptops or, instead, tablets? Their argument (i.e. tablets are more useful) is justified because of two reasons: The first, tablet technologies are cheaper. Hence, it is economically feasible. Another reason to support their argument is that students are more in need to search the net and to read than writing or performing mathematical and statistical analysis. Their claim is based upon the fact that students should be supported to expand their readings and knowledge through browsing the net and other information sources.

\section{Literature Review}

The tablet technology is relatively new. Thus, the publications in this field can be relatively rare. However, there are many studies that focus on this technology. There are applications in medicine (Horng, et al., 2012), education (Alvarez et al., 2011; Ferrer et al., 2011), and many other fields (Moberg et al., 2010). For example, Alvarez and his colleagues (Alvarez et al., 2011) make a comparative study between tablet technology and PC's to find out the best tool for teaching environment. Moberg and his research team used the tablet technology to study the impact and competition in the newspapers market (Moberg et al., 2010). In the field of medicine, Horng and his teammates studied the importance of low cost tablet technology in the emergency room (Horng et al., 2012). Turner and Libarkin studies the earth phonomena through a novel application of tablet technology.

All researches were applications and study fields of the tablet technology. However, Abbas (2012) studied the obstacles and shortcomings against the iPad adoption in the State of Kuwait. 


\section{Research Problem}

Our research mainly focuses on study the types of usages that can be considered as a motivational factors behind adopting the tablet technology. Mainly, our research tries to study the types of uses of the tablet technology among university and college level students.

The tablet technology is defined by Webopedia.com as "Spelled tablet $P C$, a type of notebook computer that has an LCD screen on which the user can write using a special-purpose pen, or stylus.

(Webopedia, 2012). Wikipedia defines tablet technology as "A tablet computer, or a tablet, is a mobile computer, larger than a mobile phone or personal digital assistant, integrated into a flat touch screen and primarily operated by touching the screen rather than using a physical keyboard. It often uses an onscreen virtual keyboard, a passive stylus pen, or a digital pen." (Wikipedia, 2012).

Hence, tablet technology mainly is a computer with LCD touchable screen that provides the user with all features (keyboard, software selections, output, browsing, etc.). In 2010 Apple released its iPad version of the tablet technology. Since then, the technology is still flourishing and expanding exponentially and since then the company reached a commercial success worldwide. In addition to The the iPad (Apple), other companies followed the in and joined the race such as Galaxy (Samsung), TouchPad (HP), Xoom (Motorola), and PlayBook (BlackBerry), whom all gaining more market share and are taking the lead in the computing field compared to old technologies such as laptops and desktops.

Here we try to focus our attention on the types of uses. As it is obvious from previous sections, we are only interested in studying the types of tablet technology uses by college level students, and hence it is going to be our study population.

The research focuses precisely answering the following questions: What are the most uses by college level students, is there any gender differences behind tablet technology uses? Does the academic background affects the types of uses?

\section{Data Collection and Frequencies}

The sample study of our research is 345 of Kuwait University students. Students belong to different colleges and many backgrounds. As we explained in the previous discussion, our concentration over Kuwait University students due to the strategic plan by the administration to equip all students with this technology. Therefore, we concentrated our study over students from different colleges.

The majority of our students are female (258, 74.8\%) (see Table 1). Most subjects age in the sample are in the range between 18 and 24 (290, 84.2\%) (see Table 2). There are around 15 colleges in Kuwait University (see Table 3 for student distribution among colleges). The majority of our sample belongs to B- grade $(82$, $24.6 \%)$ followed by the grade B $(58,16.8 \%)$ (see Table 4 for students grades distribution and frequency). Almost 90 percent of the study sample is not married $(300,87 \%)$ (see Table 5 for marital status). Around 65 percent of our sample size uses the Internet for more than 6 years $(221$, $64.6 \%$ ), followed by the group of $4-6$ years, which reflects that the Internet is a high demand by this sector of the Kuwaiti society due to their life commitments as being in the academia lifestyle (see Table 7 for more frequencies on Internet experience).

Before we begin our data collection stage, we made a review to the literature to explore the most well-known types of uses.

During this pilot study, we used student of Management Information Systems course to be our pilot study. We discussed the matter and presented to them the types of technologies, including the tablet technology. After the discussion, we collected their most usages of this technology through writing down in a piece of paper the usages beginning from the most to least types of uses (See Table 9). 
We used the data that were collected in the pilot study and during the qualitative approach of the research to build our research list of usages. The full list of uses were been built out of the output from the qualitative stage in the pilot study as well as the previous research and publications in this field.

After collecting the most frequent uses during the pilot study stage, we built our research instrument. We were able to collect 345 items. Table 10 is list of most used purposes of the iPad technology by the Kuwait University students. In order to test the reliability, we ran the reliability test and found the Cronbach Alpha $=.853$ (see Table $11)$, which is scientifically approved.

The factor loadings are presented in Table 12 . The variance initially was low $\left(\sigma^{2}=63\right)$. Then we refined the test and ran it by taking out some constructs. The total variance explained is $\sigma^{2}=71.384$ with 14 constructs only. Table 12 presents the factor loading of the most frequent uses of the iPad technology by Kuwait University Students. Note that we took out some uses due to the poor loadings. Clearly from the factor loadings we find that the uses are loaded over 6 factors. The factors can be named as 1) office uses (for presentation and lecturing, using OFFICE applications, and studying tool), 2) media (viewing TV programs and listening to Internet radio), 3) synchronous communication (Internet telephony and video talking), 4) social gathering (social networking and locating sites), 5) Knowledge tool (News and reading e-books), and finally 6) entertainment (e-gaming and easy to use).

The important note that we can make regarding our results can be found in Table 13. Table 13 shows the association test (Chi-square). It is clear that Gender has significant $p$-value (less than alpha value which is 0.05 or less) against Internet telephony (0.013), e-gaming (0.058), social networking (0.023), presentations and lecturing (0.004), listening to Internet radio
(0.001), photography (0.002), and use for video talking (0.010). The academic background shows a significant $\mathrm{p}$-value only against viewing TV (0.027).

\section{Conclusion, Limitations, and Future Research}

We presented our research regarding the types of uses of the tablet technology (iPad) in the State of Kuwait. We found that there are 14 constructs that are most frequent by the students of Kuwait University. We found that games, Internet, and socializing are the most frequent uses among college level students in the State of Kuwait.

Moreover, the association chi-square test shows that there are dependencies between sex and seven usages and only one use has significant Chi-square p-value against academic background. This means that all tablet uses are indifferent for our sample study according to their academic background except for viewing TV programs, where we found that there some significance. However, gender was significant against many uses, which were discussed in the previous section.

Our study has has limitations, though. The most noticeable limitation is that we didn't study the whole society. Our focus on college level students may not reveal the whole Kuwaiti society attitude. Thus, it is important to use another sample size in order to generalize the conclusions.

Our research sheds light over different perspectives. The first it emphasizes to study the constructs that affect and types of uses of the iPad. Another important point that can be studied is to understand the associations between the uses and demographics of students. A third important issue that can be studied is the type of uses by the whole Kuwaiti society. Fourth, we may need to understand, if any, the differences between cultures and societies. 
Table 1. Gender Frequency

\begin{tabular}{|c|c|c|c|c|c|}
\hline Sex Code & & & & & \\
\hline & Frequency & Percent & Valid Percent & Cumulative Percent & \\
\hline Sex & Male & 87 & 25.2 & 25.2 & 25.2 \\
\hline & Female & 258 & 74.8 & 74.8 & 100.0 \\
\hline & Total & 345 & 100.0 & 100.0 & \\
\hline
\end{tabular}

Table 2. Age Frequency

\begin{tabular}{|c|c|c|c|c|c|}
\hline Age Code & & & & & \\
\hline & Frequency & Percent & Valid Percent & Cumulative Percent & \\
\hline Valid & $<16$ & 3 & .9 & .9 & .9 \\
\hline & $<18$ & 20 & 5.8 & 5.8 & 6.7 \\
\hline & $<20$ & 130 & 37.7 & 37.8 & 44.5 \\
\hline & $<24$ & 160 & 46.4 & 46.5 & 91.0 \\
\hline & 24 and up & 31 & 9.0 & 9.0 & 100.0 \\
\hline & Total & 344 & 99.7 & 100.0 & \\
\hline Missing & System & 1 & .3 & & \\
\hline Total & 345 & 100.0 & & & \\
\hline
\end{tabular}

Table 3. Colleges Frequency

\begin{tabular}{|c|c|c|c|c|c|}
\hline College Codes & & & & \\
\hline & Frequency & Percent & Valid Percent & Cumulative Percent & \\
\hline Valid & Law & 8 & 2.3 & 2.3 & 2.3 \\
\hline & Art & 10 & 2.9 & 2.9 & 5.2 \\
\hline & Science & 9 & 2.6 & 2.6 & 7.9 \\
\hline & Medicine & 7 & 2.0 & 2.0 & 9.9 \\
\hline & Eng and Petr. Stu & 29 & 8.4 & 8.5 & 18.4 \\
\hline & All. Health Sc. & 5 & 1.4 & 1.5 & 19.8 \\
\hline & Edu. & 16 & 4.6 & 4.7 & 24.5 \\
\hline & Islam Stu. & 3 & .9 & .9 & 25.4 \\
\hline & Buss. Admin. & 181 & 52.5 & 52.8 & 78.1 \\
\hline & Pharm. & 4 & 1.2 & 1.2 & 79.3 \\
\hline & Dentistry & 1 & .3 & .3 & 79.6 \\
\hline & Soc. Sci. & 16 & 4.6 & 4.7 & 84.3 \\
\hline & Eng. & 10 & 2.9 & 2.9 & 87.2 \\
\hline & Comp. Sc & 8 & 2.3 & 2.3 & 89.5 \\
\hline & Other & 36 & 10.4 & 10.5 & 100.0 \\
\hline & Total & 343 & 99.4 & 100.0 & \\
\hline System & 2 & .6 & & \\
\hline Total & 345 & 100.0 & & & \\
\hline
\end{tabular}


Table 4. Grade Frequency

\begin{tabular}{|c|c|c|c|c|c|}
\hline GPA Codes & & & & & \\
\hline & Frequency & Percent & Valid Percent & Cumulative Percent & \\
\hline Valid & A & 5 & 1.4 & 1.5 & 1.5 \\
\hline & A- & 28 & 8.1 & 8.4 & 9.9 \\
\hline & B & 43 & 12.5 & 12.9 & 22.8 \\
\hline & B & 58 & 16.8 & 17.4 & 40.1 \\
\hline & B- & 82 & 23.8 & 24.6 & 64.7 \\
\hline & C+ & 41 & 11.9 & 12.3 & 76.9 \\
\hline & C & 53 & 15.4 & 15.9 & 92.8 \\
\hline & C- & 21 & 6.1 & 6.3 & 99.1 \\
\hline & D & 1 & .3 & .3 & 99.4 \\
\hline & D & 2 & .6 & .6 & 100.0 \\
\hline & Total & 334 & 96.8 & 100.0 & \\
\hline Missing & System & 11 & 3.2 & & \\
\hline Total & 345 & 100.0 & & & \\
\hline
\end{tabular}

Table 5. Marital Status Frequency

\begin{tabular}{|c|c|c|c|c|c|}
\hline Marital Status Codes & & & & & \\
\hline & Frequency & Percent & Valid Percent & Cumulative Percent & \\
\hline & Married & 45 & 13.0 & 13.0 & 13.0 \\
\hline Valid & Not Married & 300 & 87.0 & 87.0 & 100.0 \\
\hline & Total & 345 & 100.0 & 100.0 & \\
\hline
\end{tabular}

Table 6. Nationality Frequency

\begin{tabular}{|c|c|c|c|c|c|}
\hline Nationality Codes & & & & & \\
\hline & Frequency & Percent & Valid Percent & Cumulative Percent & \\
\hline Valid & Kuwait & 304 & 88.1 & 88.1 & 88.1 \\
\hline & Arab & 30 & 8.7 & 8.7 & 96.8 \\
\hline & Non Arab & 11 & 3.2 & 3.2 & 100.0 \\
\hline & Total & 345 & 100.0 & 100.0 & \\
\hline
\end{tabular}

Table 7. Years Experience in Internet

\begin{tabular}{|c|c|c|c|c|c|}
\hline Years Internet Code & & & & & \\
\hline & Frequency & Percent & Valid Percent & Cumulative Percent & \\
\hline Valid & 6 yrs or more & 221 & 64.1 & 64.6 & 64.6 \\
\hline & $4-6$ yrs & 80 & 23.2 & 23.4 & 88.0 \\
\hline & $2-4$ yrs & 25 & 7.2 & 7.3 & 95.3 \\
\hline & less than 2 yrs & 16 & 4.6 & 4.7 & 100.0 \\
\hline & Total & 342 & 99.1 & 100.0 & \\
\hline Missing & System & 3 & .9 & & \\
\hline Total & 345 & 100.0 & & & \\
\hline
\end{tabular}


Table 8. Daily Internet Usage (In Hours) Frequency

\begin{tabular}{|c|c|c|c|c|c|}
\hline $\begin{array}{c}\text { Daily Internet Usage } \\
\text { Codes }\end{array}$ & Frequency & Percent & $\begin{array}{c}\text { Valid } \\
\text { Percent }\end{array}$ & $\begin{array}{c}\text { Cumulative } \\
\text { Percent }\end{array}$ & \\
\hline & $>5 \mathrm{hrs}$ & 136 & 39.4 & 39.4 & 39.4 \\
\hline Valid & $3-5 \mathrm{hrs}$ & 87 & 25.2 & 25.2 & 64.6 \\
\hline & $1-3 \mathrm{hrs}$ & 72 & 20.9 & 20.9 & 85.5 \\
\hline & $<1 \mathrm{hr}$ & 17 & 4.9 & 4.9 & 90.4 \\
\hline & $2-5 \mathrm{hrs}$ & 20 & 5.8 & 5.8 & 96.2 \\
& weekly & & & 2.6 & 98.8 \\
\hline & $<2$ hrs weekly & 9 & 2.6 & 2.6 & 100.0 \\
\hline & rarely & 4 & 1.2 & 1.2 & \\
\hline & Total & 345 & 100.0 & 100.0 & \\
\hline
\end{tabular}

Table 9. Uses of Tablet Technology (iPad) during Pilot Study

\begin{tabular}{|c|c|}
\hline Type of Usage & No. of Students \\
\hline Research & 6 \\
\hline Reading & 8 \\
\hline Games & 32 \\
\hline Internet & 26 \\
\hline Movies & 3 \\
\hline Writing notes & 2 \\
\hline Newspaper & 1 \\
\hline forums & 1 \\
\hline Everything we use the laptop for & 7 \\
\hline YouTube & 3 \\
\hline Focial networks & 13 \\
\hline twitter & 3 \\
\hline camera & 4 \\
\hline translation & 5 \\
\hline google search & 1 \\
\hline photographic design & 1 \\
\hline media & 2 \\
\hline
\end{tabular}


Table 10. Uses of iPad Technology

\begin{tabular}{|c|c|c|c|}
\hline Item Statistics & & & \\
\hline & Mean & Std. Deviation & $\mathrm{N}$ \\
\hline Net Search & 4.07 & 1.092 & 322 \\
\hline e-mail & 3.80 & 1.242 & 322 \\
\hline Reading e-Books & 3.11 & 1.361 & 322 \\
\hline Photography & 3.97 & 1.138 & 322 \\
\hline Listening Music & 4.10 & 1.141 & 322 \\
\hline Internet Telephony & 3.18 & 1.376 & 322 \\
\hline e-gaming & 3.89 & 1.256 & 322 \\
\hline Weather and News & 3.36 & 1.318 & 322 \\
\hline Movies & 3.54 & 1.340 & 322 \\
\hline Easy to use compared to Laptops and PCs & 4.07 & 1.057 & 322 \\
\hline App Store applications & 4.19 & 1.035 & 322 \\
\hline Maps and locating sites & 3.42 & 1.271 & 322 \\
\hline Social Networking & 4.16 & 1.088 & 322 \\
\hline Studying tool & 3.75 & 1.202 & 322 \\
\hline For presentations and lecturing & 3.16 & 1.309 & 322 \\
\hline Viewing TV programs & 2.76 & 1.323 & 322 \\
\hline Listening to Internet radio & 2.85 & 1.311 & 322 \\
\hline Using OFFICE applications & 2.91 & 1.306 & 322 \\
\hline Use it for Photography & 3.33 & 1.371 & 322 \\
\hline Use it for video talking & 3.34 & 1.365 & 322 \\
\hline
\end{tabular}

Table 11. Reliability Test of the Study

\begin{tabular}{|c|c|c|}
\hline Reliability Statistics & & \\
\hline Cronbach's Alpha & Cronbach's Alpha Based on Standardized Items & N of Items \\
\hline .851 & .853 & 20 \\
\hline
\end{tabular}

Table 12. Factor Analysis of iPad Technology Uses

\begin{tabular}{|l|l|l|l|l|l|l|}
\hline Rotated Component Matrix & Component & & & & & \\
\hline & 1 & 2 & 3 & 4 & 5 & 6 \\
\hline Internet Telephony & & & .888 & & & \\
\hline e-gaming & & & & & & .718 \\
\hline Easy to use compared to Laptops and PCs & & & & & & .722 \\
\hline Social Networking & & & & .805 & & \\
\hline For presentations and lecturing & .712 & & & & & \\
\hline Viewing TV programs & & .825 & & & & \\
\hline Listening to Internet radio & & .821 & & & & \\
\hline Using OFFICE applications & .773 & & & & & \\
\hline Use it for video talking & & & .839 & & & \\
\hline e-mail & & & & & & \\
\hline Maps and locating sites & & & & .641 & & \\
\hline Weather and News & & & & & .694 & \\
\hline Studying tool & .678 & & & & & \\
\hline Reading e-Books & & & & & .748 & \\
\hline $\begin{array}{l}\text { Extraction Method: Principal Component Analysis. } \\
\text { Rotation Method: Varimax with Kaiser } \\
\text { Normalization. }\end{array}$ & & & & & & \\
\hline a. Rotation converged in 11 iterations. & & & & & & \\
\hline
\end{tabular}


Table 13. Pearson Chi-Square Test $(\propto=0.05)$

\begin{tabular}{|c|c|c|}
\hline Usage & Gender & Academic Background \\
\hline Net Search & .499 & .462 \\
\hline e-mail & .788 & .440 \\
\hline Reading e-Books & .430 & .101 \\
\hline Photography & .210 & .590 \\
\hline Listening Music & .097 & .988 \\
\hline Internet Telephony &. $\mathbf{0 1 3}$ & 322 \\
\hline e-gaming & $\mathbf{. 0 5 8}$ & .307 \\
\hline Weather and News & .508 & .925 \\
\hline Movies & .869 & .787 \\
\hline Easy to use compared to Laptops and PCs & .071 & .736 \\
\hline App Store applications & .574 & .363 \\
\hline Maps and locating sites & .399 & .856 \\
\hline Social Networking & $\mathbf{. 0 2 3}$ & .588 \\
\hline Studying tool & .406 & .509 \\
\hline For presentations and lecturing & $\mathbf{. 0 0 4}$ & .306 \\
\hline Viewing TV programs & .163 &. $\mathbf{0 2 7}$ \\
\hline Listening to Internet radio & $\mathbf{. 0 0 1}$ & .084 \\
\hline Using OFFICE applications & .460 & .187 \\
\hline Use it for Photography & $\mathbf{. 0 0 2}$ & .197 \\
\hline Use it for video talking & $\mathbf{. 0 1 0}$ & .536 \\
\hline
\end{tabular}

\section{Acknowledgment}

This research was funded by Kuwait University, Research Grant IQ 05/05.

\section{References}

Abbas, H. (2012). 'Obstacles against Adopting iPad in Kuwait,' International Academy of Business and Public Administration Disciplines. Dallas, USA, April, 2012.

Alvarez, C., Brown, C. \& Mussbaum, M. (2011). "Comparative Study of Notebooks and Tablet PCs for Fostering Face-to-Face Collaborative Learning," Computers in Human Behavior, 27 (2), 834 - 844. March 2011.

Ferrer, F., Belvis, E. \& Pamies, J. (2011). "Tablet PCs, Academic Results and Educational Inequalities," Computers \& Education, 56 (1), pp. 280 - 288. Jan. 2011.
Moberg, A., Johansson, M., Finnveden, G. \& Jonsson, A. (2010). "Printed and Tablet EPaper Newspaper from an Environmental Perspective - A Screening Life Cycle Assessment," Environmental Impact Assessment Review. 30 (3), pp. 177 - 191. April, 2010.

Turner, S. \& Libarkin, J. (2012). "Novel Applications of Tablet PCs to Investigate Expert Cognigion in the Geosciences," Computers \& Geosciences. In press, Available online Sept. 2011.

Webopedia.com. (2012). http://www.webopedia.com/TERM/T/tabl et_PC.html. 2012.

Wikipedia.com. (2012). http://en.wikipedia.org/wiki/Tablet_comp uter. 